BLS 35, No 1 2009. DOI: http://dx.doi.org/10.3765/bls.v35i1.3625

(published by the Berkeley Linguistics Society and the Linguistic Society of America)

\title{
Discourse and Scalar Structure in Non-Canonical Negation
}

\author{
PATRÍCIA AMARAL and SCOTT A. SCHWENTER \\ Stanford University and The Ohio State University
}

\section{Introduction}

This paper combines two strands of research: (i) the study of the discoursecontextual requirements on the use of non-canonical negative forms, and (ii) research on what has recently been termed the "permeable polar membrane" (Horn 2008) of approximative adverbs like English almost and barely. As regards the first, cross-linguistic studies have shown that non-canonical sentential negatives are licensed under particular discourse conditions that relate to information structure (Fretheim 1984, Espinal 1993, Zanuttini 1997, Kaiser 2006, Schwenter 2005, 2006). Regarding the second, it has been observed that the polar component of approximative adverbs is more open to contextual flexibility than their proximal component (see Li 1976, Horn 2002, Schwenter 2002, Amaral 2007 a.o.). In this paper, we focus on the negative readings of two approximative adverbs, Engl. hardly and European Portuguese (henceforth EP) mal 'barely, hardly,' and argue that their "strengthened" negative interpretations can be fleshed out in terms of constraints on the discourse structure. In our proposal, we build both on the licensing conditions of non-canonical negatives and on the scalar meaning of approximative adverbs.

The structure of the paper is as follows. In section 1, we present the Conjunctive Analysis of approximative adverbs and introduce the canonical and inverted readings of these forms. In section 2, we briefly review the literature on the licensing conditions of non-canonical negatives. Section 3 details the distribution of the inverted readings of Engl. hardly and EP mal and section 4 proposes the constraints on discourse structure effected by these inverted readings. Section 5 provides concluding remarks.

\section{The Meaning of Approximatives: Canonical and Inverted Readings}

The meaning of approximative adverbs like English almost and barely/hardly has been analyzed as the conjunction of two propositional components (Sevi 1998; Horn 2002), called "proximal" and "polar," fleshed out below in the paraphrases of examples (1) and (2), from Horn (2002): 
Patrícia Amaral and Scott A. Schwenter

(1) Gore almost won.

$\left(1^{\prime}\right)$ Gore came close to winning (proximal component) \& Gore didn't win (polar component)

(2) Bush barely/hardly won.

(2') Bush came close to not winning (proximal component) \& Bush won (polar component)

Cross-linguistically, these adverbs can license interpretations where the polar component has opposite polarity (Li 1976; Schwenter 2002; Pons and Schwenter 2005; Amaral 2006), i.e. adverbs like almost may display a positive polar component and adverbs like barely/hardly may display a negative polar component. In this paper, we will refer to these interpretations as "inverted readings" of approximative adverbs to distinguish them from the "canonical interpretations" paraphrased in (1) and (2). The canonical and the inverted interpretations of hardly are exemplified below: Whereas in (3) the sentence containing hardly expresses a proposition that entails the truth of the predicate pass the exam (as in $\left(3^{\prime}\right)$ ), in (4), the sentence containing hardly expresses a proposition that entails the negation of the predicate be in short supply, as in (4'):

(3) The final result, John hardly passed the exam, and received a low grade, and Sarah passed with a high grade and with less effort and stress.

(http://alittlebitabout.com/Articles/Education/Pareto-principle.html)

(3') John passed the exam.

(4) Title: Ten Green Announcements From the Detroit Auto Show Kick-off.

Automakers kicked off this year's North American International Auto Show yesterday with less glitz and more conspicuous frugality than in years past. But new plans for hybrid and electric models were hardly in short supply. (Following paragraphs: description of ten new announcements of hybrid and electric cars)

(http://earth2tech.com/2009/01/12/10-green-announcements-from-the-detroitauto show-kick-off)

(4') The plans for green vehicles were not in short supply.

In this paper, we focus on the inverted interpretation of hardly, as exemplified in (4). We will show how the contribution of hardly, which entails the negation of the modified predicate, differs from the meaning of the canonical sentential negator not (e.g., But new plans for hybrid and electric models were not in short supply), by proposing a set of conditions on the discourse structure that are associated with the inverted readings of approximative adverbs. 


\section{Discourse and Scalar Structure in Non-Canonical Negation}

\subsection{Differences Between barely and hardly}

Before we focus on the negative reading of hardly, it is important to distinguish this adverb from its near-synonym barely, as well as from its use as a stand-alone response particle. Consider the contrasts between the two adverbs in the following sentences: ${ }^{1}$

(5) Mary barely passed her exam.

(6) Mary hardly passed her exam.

(7) Mary BARELY passed her exam.

(8) Mary HARDLY passed her exam.

Without additional contextual modification, (5) and (6) have the same interpretation: Mary passed her exam but approximated not passing it. By contrast, (7) and (8), where the approximatives each receive a focal pitch accent, are most readily interpreted by native speakers in distinct fashion. In the case of (7), the pitch accent reinforces the proximal meaning of the adverb, i.e. the proximal component is understood as even closer to the negation of the predicate. In (8) however the interpretation of hardly is understood as that of the inverted approximative: Mary did not pass her exam, and in fact did not even come close to doing so. The focal pitch accent in (8) does not guarantee the inverted approximative interpretation (i.e. it is not criterial for this meaning "inversion"), but it does make that interpretation much easier to access in the absence of additional contextual material.

Another interesting restriction on hardly that distinguishes it clearly from barely can be appreciated in responses to yes/no-questions. In this context, hardly is actually restricted to its inverted reading; the approximative meaning is by contrast inaccessible, as shown by the possible continuations of B's response in (9) and (10):

(9) A: Did you finish writing your paper?

B: Barely/Just barely/Only barely: I finished it five minutes ago!

(10) A: Did you finish writing your paper?

B: Hardly/\#Just hardly/\#Only hardly: \# I finished it five minutes ago!

(11) A: Did you finish writing your paper?

B: Yes, but (just) barely/\#hardly.

(12) A: Did you finish writing your paper?

B: No, hardly/\#barely.

As the difference between (9) and (10) shows, modification by just or only of barely is felicitous but similar modification is not acceptable with hardly, since barely in (9) entails that B finished writing her paper while hardly in (10) entails

\footnotetext{
${ }^{1}$ Small caps are intended to signal a pitch accent on the adverb.
} 
the negated proposition, i.e. that B did not finish writing her paper. In a similar vein, the initial affirmative response particle in (11) is compatible with the positive polar component of barely, but the negative response particle in (12) only makes sense with hardly, because of the restriction of hardly to the inverted interpretation in the yes/no-question context.

\section{Licensing Conditions of Non-Canonical Negatives}

Research on the form and meaning of non-canonical negation has focused on sentential negatives that are formally distinct from the canonical or "unmarked" way of expressing sentential negation in a given language (Hansen 2008; Schwenter 2005, 2006). Contrasts between canonical and non-canonical sentential negatives, respectively, can be seen in pairs like non V vs. non V mica in Italian (Zanuttini 1997) or no V vs. no V pas in Catalan (Espinal 1993), where a postverbal nominal minimizer (mica '(a) crumb'; pas '(a) step') have been reanalyzed as part of a bipartite sentential negative. The goal of much of this work has been to determine the specific licensing conditions for non-canonical negatives vis-àvis their canonical counterparts.

On an intuitive level, non-canonical negatives (NCNs) are typically treated as "emphatic." NCNs have also been called presuppositional negatives, which contrast with their non-presuppositional canonical negative counterparts (Zanuttini 1997): NCNs like non V mica in Italian deny a proposition that is already entered into the discourse record, and is thereby "presupposed," while CNs do not display the same requirement on the status of the propositions they modify. More recent work has focused on information structural explanations (Schwenter 2005, Hansen 2008, Kaiser 2006, Fretheim 1984): NCNs differ from canonical negatives in that they pose pragmatic constraints on the discourse status of the propositions that they can modify. In most instances of NCNs studied to date, the negated proposition must be discourse-old (cf. Prince 1992; Birner 2006), i.e. it must be either evoked in or inferentially linked to prior discourse. ${ }^{2}$ But crucially, different NCNs, both across languages and in the same language (see Schwenter 2005, 2006), have different information structure constraints.

A standard example of a NCN is the EP construction NEG-NADA, formed by the adverb of negation não 'not' in preverbal position and the negative indefinite pronoun nada 'nothing' in post-verbal position (after a finite verb). In EP, the felicitous use of this construction is only licensed in the context of a discourse-old proposition that has been asserted in the immediately prior context by an interlocutor (Schwenter 2008). So, in (13), while the use of the canonical sentential negator (as negative response particle) não 'no, not' is felicitous in B1's response, the occurrence of NEG-NADA in B2's response is infelicitous, since the denied

\footnotetext{
${ }^{2}$ Under this definition, which corresponds closely to Birner's (2006) revision of Prince's (1992) original model of given/new information, discourse-old propositions could be either familiar or unfamiliar to the hearer.
} 


\section{Discourse and Scalar Structure in Non-Canonical Negation}

proposition, the proposition that Pedro buys a house in the near future, is not asserted in A's utterance:

$$
\text { A: O Pedro vai comprar uma casa? }
$$

B1: Não.

B2: \#Não vai nada.

On the other hand, in (14) both the canonical and the non-canonical negations are acceptable since the denied proposition enters the discourse record as an assertion. In other words, the non-canonical form contributes a propositional denial (like the canonical form) but is pragmatically stronger in that its use is more restricted than that of sentential não. ${ }^{3}$ The claim that the EP construction is a strengthened negator can be tested by applying the or at least test for pragmatic scales (Horn 1972, Israel 1996), as in B1 and B2's elaborations on the initial response:

\section{A: O Pedro vai comprar uma casa. \\ 'Pedro is going to buy a house.'}

B1: Não, não vai. B2: Não vai nada!

$\mathrm{B} 1$ : $(\mathrm{CN}) \mathrm{Ou}$ pelo menos ainda não, porque não tem dinheiro.

B2: $(\mathrm{NCN})$ \#Ou pelo menos ainda não, porque não tem dinheiro. 'No, or at least not yet, because he doesn't have the money.'

As these continuations illustrate, any weakening of the negation with the or at least test is infelicitous with the $\mathrm{NCN}$ but perfectly fine with the $\mathrm{CN}$ construction.

In the following, we show that the distribution of the inverted readings of hardly and $\mathrm{mal}$ is more constrained than the distribution of canonical negatives (Engl. not, EP não). The negative interpretation of mal is restricted to a specific construction: The adverb modifies an epistemic stative verb (e.g. saber 'to know,' imaginar 'to imagine,' acreditar 'to believe') occurring in a form with imperfective aspectual value, e.g. the imperfective past (Imperfeito do Indicativo), and the verb selects for a sentential complement (in (15), introduced by the complementizer que). The subject, if overtly expressed, occurs typically in post-verbal position, although this is not obligatory. This construction is schematically represented in (15):

\footnotetext{
${ }^{3}$ The NEG-NADA construction applies only to propositions which have a certain pragmatic force: an asserted proposition is a proposal to update and change the discourse record, possibly in a controversial way (cf. Stalnaker 1978). The pragmatic restriction to denials of propositions with such a status explains the intuitively "emphatic" meaning of this construction. Given the privileged status of assertions, it may be the case that the NEG-NADA construction is associated with an implication of certainty on the part of the speaker (hence contributing to the strength of the speaker's commitment to the denial), but this is beyond the scope of this paper.
} 
Patrícia Amaral and Scott A. Schwenter

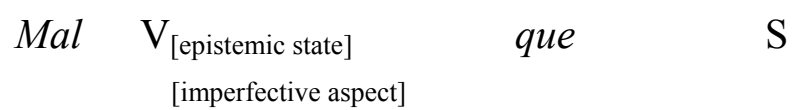

In this construction, there is an implication as to the speaker's commitment to the truth of the proposition expressed by S.

Although the negative reading of hardly is more lexicalized than the negative reading of mal, in both cases the inverted readings of the adverbs are constrained by discourse structure. In section 4 , we will show how the licensing conditions of the inverted readings make it possible to elucidate the notion of "strengthened negation."

\section{Distribution of the Inverted Readings of English hardly and EP mal}

Several diagnostics can be used to test the restricted distribution of the inverted readings of hardly and mal. Starting with hardly, whereas both hardly and no are felicitous in proposition denials, as in B1 in (16), only no is acceptable in expressing metalinguistic negation (Horn 1985, 1989), as shown by the contrast between $\mathrm{B} 2$ and $\mathrm{B} 3$ :
A: John is pretty tall.
B1: He is not/hardly tall, he is actually very short. (proposition denial)
B2: He is not TALL, he is GARGANTUAN.
B3: \#He is hardly TALL, he is GARGANTUAN.

This test shows that hardly invariably indicates a proposition denial, hence the infelicity of B3.

The test of "redundant affirmation" (Horn 1991) also shows a difference between the behavior of the canonical and the non-canonical negatives. According to Horn, an "informationally redundant affirmation" is discourse-acceptable even after its content has been entailed or presupposed in the context as long as it is rhetorically opposed to the preceding utterance. Redundant affirmation is acceptable with $n o$, as in (17), but not with hardly, as shown by the infelicity of (18):

A: Did you finish writing your paper?

B: No, but I'll be done in a few minutes.
A: Did you finish writing your paper?
B: \#Hardly, but I'll be done in a few minutes.

Whereas the canonical negative form no in (17) is compatible with the rhetorically opposed proposition introduced by the but-clause, hardly is not acceptable in the same context.

As for mal, the or at least test shows that the inverted reading is infelicitous in a context inducing the weakening of the negation, whereas in such a context the canonical form não is acceptable: 


\section{Discourse and Scalar Structure in Non-Canonical Negation}

(19) O João não imaginava que a água ia gelar nas torneiras, ou pelo menos que ia ficar tanto frio.

'João did not $(\mathrm{CN})$ imagine that the tap water would freeze, or at least that the weather would become so cold.'

(20) \#O João mal imaginava que a água ia gelar nas torneiras, ou pelo menos que ia ficar tanto frio.

'João did not (mal: NCN) imagine that the tap water would freeze, or at least that the weather would become so cold.'

Finally, both hardly and mal are not licensed as denials of a merely shared prior belief, as shown by (21) and (22) below, in which the counterpart canonical negatives are perfectly felicitous:

(21) (Context: The interlocutors believed that John was going to move to Michigan)

A: Guess what? \#John is hardly moving to Michigan! vs. Guess what? John isn't moving to Michigan!

(22) (Context: The interlocutors believed that João thought that Ana was going to move from Portugal to the USA)

A: Sabes uma coisa? \#O João mal sabe que a Ana não vai mudar de país. vs. Sabes uma coisa? O João não sabe que a Ana não vai mudar de país.

'You know what? João does not (mal/não) know that Ana is not going to move to a different country.'

The infelicitous use of hardly and mal in (21) and (22) shows that the approximative adverbs contribute the denial of a proposition whose salience must be established in the previous linguistic context. The existence of a shared belief which has not been linguistically expressed or cannot be inferred from a previous utterance is not enough for the felicity of the inverted reading.

Example (4), partially repeated here, shows how the discourse-old proposition denied by hardly may be unfamiliar to the hearer and inferentially linked to the previous discourse (Birner 2006):

(4) Automakers kicked off this year's North American International Auto Show yesterday with less glitz and more conspicuous frugality than in years past. But new plans for hybrid and electric models were hardly in short supply.

From the assertion that this year there is "less glitz and more conspicuous frugality than in years past" one may infer that there are fewer plans for new auto technology at this year's show, e.g. fewer hybrid and electric models. Thus, 
hardly is denying a contextually-accessible proposition that can be inferred from prior linguistically explicit material.

\section{Discourse Conditions on the Inverted Readings of hardly and mal}

We propose that the negative readings of hardly and mal are licensed in a set of contexts that meet the following conditions:

(i) The linguistic context entails a set of propositions that are structured, namely, that are ordered by pragmatic entailment (in the sense of Fauconnier 1975) in a contextually determined scale;

(ii) There is a proposition accessible in the context (either explicitly expressed or that can be inferred from a proposition expressed in the previous linguistic context), the context proposition or cp (cf. Kay 1990), which is part of the common ground of speaker and hearer at the time of utterance;

(iii) The proposition expressed by the sentence containing the approximative adverb, ${ }^{4}$ the text proposition or $t p$, pragmatically entails the negation of $\mathrm{cp}$.

To make this more concrete, we will consider the application of these conditions to the dialogic example in (23), where the set of structured propositions that are entailed by the context is given in $\left(23^{\prime}\right)$.

(23) FBI agent: Was Luke unfriendly to you?

Luke's ex-classmate: Hardly, he was actually very nice. He even apologized for his behavior when we were in high school.

[from the CBS TV show "Without a Trace"]

(23') cp: Luke was unfriendly to his classmate.

$\sim$ cp: Luke was not unfriendly to his classmate.

tp: Luke was at least friendly.

In this case, the cp is accessible and part of the common ground of the interlocutors when the sentence containing hardly is uttered since it is one of the possible answers to the question asked by the FBI agent in (23). The negation of the context proposition $(\sim \mathrm{cp})$ is obtained by applying negation to the predicate be unfriendly, as in (23'). The response particle hardly contributes a proposition (tp) that entails the negation of the context proposition, according to the Horn scale $<$ friendly, not unfriendly $>$, and the following assertion by Luke's ex-classmate introduces a stronger term on the same scale: <very nice, friendly $>$. The intuitive notion of "strengthened" negation can be fleshed out by looking at $\left(23^{\prime}\right)$ : While the canonical negative operator applied to $\mathrm{cp}$ would yield the negation of the property unfriendly (i.e. not unfriendly, cf. $\sim \mathrm{cp}$ ), the contribution of hardly is to

\footnotetext{
${ }^{4}$ For $m a l$, the tp is the proposition expressed by the complement clause of the epistemic verb over which the adverb has scope.
} 


\section{Discourse and Scalar Structure in Non-Canonical Negation}

introduce a property that is a stronger scalar alternative than not unfriendly (see Horn 1989). Note also the co-occurrence of the marker of counterexpectation actually and the scalar adverb even.

A similar analysis can be extended to (24), which exemplifies how the ordered set of propositions to which the $\mathrm{cp}$ and the tp belong may arise in a particular context:

(24) Q: Why are the roads littered with dead possums? - Are they really that stupid?

A: Opossums have small brains but they're hardly stupid. Their brains have evolved sufficiently to insure the survival of their species. Cars and other dangers of the modern world are relatively new - there hasn't been enough time to develop a defense.

(http://www.clcookphoto.com/possum.htm)

(24') cp: opossums are stupid

$\sim$ cp: opossums are not stupid

tp: opossums are capable animals

In (24), the second question in Q introduces the cp, situating opossums at a low point on a scale ordering animals by their intelligence and/or capability (from low values to high values of intelligence/capability). The hardly-marked response in A denies this proposition and implicates that opossums are actually far from stupid, a position that is further supported by the explanation that follows.

In (25), we observe the same contextual restrictions on the inverted interpretation of mal, as shown in $\left(25^{\prime}\right)$ :

O EF Language, o Merit Cup e o Innovation Kvaerner foram apanhados pela calmaria. "Lutámos durante quatro horas para percorrer cem metros em dez minutos. E parece que isto não vai melhorar nas próximas vinte horas," exclamou Paul Cayard, do EF Language, mal sabendo ainda que a sua táctica de navegação renderia óptimos dividendos dias depois. (Cetempúblico, ext 54806)

'The EF Language, the Merit Cup and the Innovation Kvaerner [names of yachts] were caught in the calm waters. "We've fought for four hours to advance $100 \mathrm{~m}$ in ten minutes. And it seems that this is not going to improve in the next twenty hours," said Paul Cayard from EF Language. Little ( $\mathrm{mal}$ ) did he know at that point that his navigation technique would yield great results some days later.' 
$\left(25^{\prime}\right)$ cp: The EF Language's place in the race does not improve.

$\sim \mathrm{cp}$ : It is not true that the EF Language's place in the race does not improve, i.e. by double negation, the EF Language's place in the race improves.

tp: The captain's navigation technique yields great results.

In (25), the cp is explicitly provided in the discourse ("(And it seems that) [the EF Language's place in the race] is not going to improve"). The negation of this proposition is given as $\sim \mathrm{cp}$ in $\left(25^{\prime}\right)$. The complement clause of the epistemic verb saber 'to know' denotes the proposition that the captain's technique yields great results (the tp), from which it can be inferred that the place of the sailing boat in the race improves a lot. This proposition constitutes a stronger propositional alternative than $\sim \mathrm{cp}$ on the contextually-relevant scale. In other words, the tp entails the lower-ranked proposition $\sim \mathrm{cp}$ "The place of the EF Language in the race improves," assuming the scale <yields great results, improves $>$. Hence, what underlies the pragmatic effect of the "strengthened negation" is the ordering of the tp on the relevant scale: The tp is a propositional scalar alternative which is more informative (in the sense of Fauconnier 1975) than the denial of the cp.

To sum up, we have argued that the inverted readings of Engl. hardly and EP mal differ from sentential negation in that they are constrained by discourse structure. Specifically, we have argued that the inverted readings contribute a denial of a proposition, the context proposition (cp), whose salience has to be contextually established (discourse-old, in the sense of Prince 1992 and Birner 2006). Our proposal makes an explicit claim about the way in which hardly and mal are "strengthened negators," hence differing from canonical negatives. The denial they contribute operates on a scalar model of propositions ordered by pragmatic entailment, by selecting a propositional alternative on the scale which is pragmatically more informative than the $\mathrm{cp}$ : The proposition expressed by the sentence containing the inverted approximative entails the negation of $\mathrm{cp}$.

\section{Conclusions}

In this paper, we have analyzed the inverted readings of hardly and mal as NCNs. We have shown that their felicitous use displays information-structure constraints like other NCNs (e.g. minimizers in bipartite negative constructions). We have argued that the notion of "strengthened negation" can be fleshed out in terms of constraints on the discourse structure that involve pragmatic scales, thereby providing an empirical basis for the widespread view that NCNs are "emphatic" negators. Further research on these topics should explore the relation between the inverted readings of almost approximatives (as explored e.g. by Schwenter 2002) and hardly approximatives such as those investigated in this paper. 


\section{Discourse and Scalar Structure in Non-Canonical Negation}

\section{References}

Amaral, Patrícia. 2006. The polysemy of mal in European Portuguese: A diachronic analysis. Journal of Historical Pragmatics 7(1):1-37.

Amaral, Patrícia. 2007. The meaning of approximative adverbs: Evidence from European Portuguese. Ph.D. diss., Ohio State University.

Birner, Betty J. 2006. Semantic and pragmatic contributions to information status. Acta Linguistica Hafniensia 38:14-32.

Espinal, Maria Teresa. 1993. The interpretation of no-pas in Catalan. Journal of Pragmatics 26:475-523.

Fauconnier, Gilles. 1975. Pragmatic scales and logical structure. Linguistic Inquiry 4:353-375.

Fretheim, Thorstein. 1984. Denials and other negatives. In Knut Bergslund et al., eds., Riepmocála, Essays in honour of Knut Bergslund: Presented on the occasion of his seventieth birthday, 49-65. Oslo: Novus Forlag.

Hansen, Maj-Britt Mosegaard. 2008. The grammaticalization of negative reinforcers in old and middle French: A discourse-functional approach. Ms., University of Manchester.

Horn, Laurence R. 1972. On the semantic properties of logical operators in English. Ph.D. diss., University of California, Los Angeles.

Horn, Laurence R. 1985. Metalinguistic negation and pragmatic ambiguity. Language 76:121-174.

Horn, Laurence R. 1989. A natural history of negation. Chicago: University of Chicago Press.

Horn, Laurence R. 1991. Given as new: When redundant affirmation isn't. Journal of Pragmatics 15:313-336.

Horn, Laurence R. 2002. Assertoric inertia and NPI licensing. Chicago Linguistics Society 38-2: The Panels, 55-82.

Horn, Laurence R. 2008. Almost et al.: Scalar adverbs revisited. Ms., Yale University.

Israel, Michael. 1996. Polarity sensitivity as lexical semantics. Linguistics and Philosophy 19:619-666.

Kaiser, Elsi. 2006. Negation and the left periphery in Finnish. Lingua 116:314350.

Kay, Paul. 1990. Even. Linguistics and Philosophy 8:59-111.

Li, Charles. 1976. A functional explanation for an unexpected case of ambiguity (S or $\sim \mathrm{S}$ ). In Alphonse Juilland, ed., Linguistic studies offered to Joseph Greenberg on the occasion of his sixtieth birthday, 527-535. Saratoga, CA: Anna Libri.

Pons Bordería, Salvador, and Scott A. Schwenter. 2005. Polar meaning and "expletive" negation in approximative adverbs: Spanish por poco (no). Journal of Historical Pragmatics 6:262-282. 
Prince, Ellen F. 1992. The ZPG letter: Subjects, definiteness, and informationstatus. In William Mann and Sandra A. Thompson, eds., Discourse description: Diverse analyses of a fundraising text, 295-325. Amsterdam: John Benjamins.

Schwenter, Scott A. 2002. Discourse context and polysemy: Spanish casi. In Caroline Wiltshire and Joaquim Camps, eds., Romance phonology and variation: Selected papers from the 30th Linguistic Symposium on Romance Languages, 161-175. Amsterdam: John Benjamins.

Schwenter, Scott A. 2005. The pragmatics of negation in Brazilian Portuguese. Lingua 115:1427-1456.

Schwenter, Scott A. 2006. Fine-tuning Jespersen's cycle. In Betty J. Birner and Gregory Ward, eds., Drawing the boundaries of meaning: Neo-Gricean studies in honor of Laurence R. Horn, 327-344. Amsterdam: Benjamins.

Schwenter, Scott A. 2008. Dialogicity and the emergence of sentential negation in (Brazilian) Portuguese. Paper presented at New Reflections on Grammaticalization 4, Leuven, Belgium.

Sevi, Aldo. 1998. A Semantics for almost and barely. M.A. thesis, Tel-Aviv University.

Stalnaker, Robert C. 1978. Assertion. In Peter Cole, ed., Syntax and semantics 9: Pragmatics, 315-332. New York: Academic Press.

Zanuttini, Raffaella. 1997. Negation and clausal structure. Oxford: Oxford University Press.

Patrícia Amaral

Dept. of Linguistics

Margaret Jacks Hall

450 Serra Mall, Bldg 460

Stanford, CA 94305-2150

pamaral@stanford.edu

Scott Schwenter

Dept. of Spanish and Portuguese

The Ohio State University

298 Hagerty Hall

1775 College Rd.

Columbus, OH 43210-1340

schwenter.1@osu.edu 